\title{
The Contribution of Dynamic Psychotherapy to Forensic Psychiatry and Vice Versa*
}

\author{
By MurRay Cox, Consultant Psychotherapist, Broadmoor Hospital
}

Many activities undertaken by the forensic psychiatrist have nothing to do with dynamic psychotherapy, and rightly so. Likewise, the main thrust of dynamic psychotherapy, is independent of forensic issues. Nevertheless, there is a preserve of clinical responsibility within forensic psychiatry which, on occasion, justly invokes the aid of dynamic psychotherapy. This may be when the scope of the patient's treatment, already initiated by the forensic psychiatrist, needs to be enlarged to include dynamic psychotherapy, or when assessment of intrapsychic processes calls for prolonged engagement with the patient at depth, within the proximity provided in a therapeutic setting. For example, the complex task of disentangling amnesia or pseudo-amnesia from repression is one which no one experienced in either field would regard as easy.

One of the therapist's tasks is to try to discern how much of his 'lost' history the patient can bear at the time of the therapeutic session. He may suffer from genuine amnesia for an episode in his life in which, momentarily, though with lasting consequences, he became a killer. His amnesia may be due to the unconscious defence mechanism of repression, because the memory of the incident would be intolerable and too ego-dystonic to permit recall. Or he may furnish evidence of pseudo-amnesia as a conscious 'excuse', which might influence 'disposal'. In areas of debate such as this, forensic psychiatry and dynamic psychotherapy ask searching questions of each other. The psychotherapist may therefore be called upon to assist his colleague in the forensic field not only by providing 'therapy' for mutual patients, but for the assessment of endopsychic factors. This is only possible in a therapeutic setting, because the quality of material produced 'spontaneously' in therapeutic space is frequently of a different order from that accessible, to even the most skilled clinician, during a formal assessment 'interview'.

For his part, the psychotherapist whose work is within the wider field of conventional dynamic psychotherapy may turn in haste, and with great anxiety, to the forensic psychiatrist to tap his experience of interpersonal confrontation. The questioning, which is often in camera, comes from a relative lack of experience of that watershed at which intrapsychic forces burst their bounds and interpersonal disaster ensues. The point at which aggressive fantasy becomes aggressive fact is the point at which the psychotherapist may need forensic reorientation and reassurance. In my view, there is a potential source of danger in some 'conventional' psy-

-This is a summary, the complete text, with illustrative examples, quotations and bibliography, is to be published elsewhere. chotherapy supervision situations. By this I mean that fears which the trainee may express, in relation to the patient's stated aggressive fantasy, may be dangerously devalued. If the supervisor's perception is restricted to the circumscribed presumption that such feelings engendered in the trainee must be restricted counter-transference phenomena, and not a reality-based warning, disaster may ensue. It is a cautionary tale for all psychiatrists, and psychotherapists in particular, that it is possible for unresolved transference to motivate an assault, maybe even a fatal assault.

It would be arrogant and dishonest to imply that a psychotherapist immersed in a forensic setting has the answer to such daunting questions. It is, however, indicative of a much needed preserve of reciprocity between the specialties under consideration, that such issues as these form an almost daily ingredient among other topics discussed with colleagues.

There are several terms which are frequently used in the shared professional vernacular of both fields, though they often have remarkably different connotations; viz. Identity, Boundary, Borderline Phenomena, Security, and Containment. The term 'The Holding Environment' describes aspects both of the quality of life possible within the secure perimeter of a custodial institutionnd also of the emotional holding-experience possible within a therapeutic relationship.

The importance of Time and Timing in both fields cannot be exaggerated. In a setting where many patients and therapists meet 'without limit of time', time and timing, paradoxically, become more rather than less important.

Later today you will be hearing the first Peter Scott Memorial Lecture. Approximately ten years ago when I was 'getting the feeling of the place', I attended a case conference conducted by Peter Scott. I have such a vivid recollection of the quiet, direct and unavoidable way in which he looked over his half-glasses and said to the patient 'Looking back on it all now... how do you feel?' In this question he had touched upon a common chord in forensic psychiatry and dynamic psychotherapy, because each is concerned to ask this question, implicitly or explicitly, and future therapeutic strategy will depend upon the nature of the answer and whether it is provisional or final.

\section{'Looking back on it ell now ...'}

The questions the clinician may find he is asking himself as he asks the patient to 'Look back on it all now' are: 'When do you look back?' 'How far back do you look?' 'How long do you look back?' 
Peter Scott's question carried so many implicit questions that the answer the patient chose to give said much about the question he thought he was being asked! It is a perfect example of an invitational question. For example, the reply might refer to (a) the feelings on first being admitted to Broadmoor; (b) the trial; (c) the offence, e.g. hearing the victim scream or the fear of being discovered; (d) preparation for the offence, e.g. taking alcohol to give him 'the bottle'. These are all standard forensic issues so that 'looking back on it all now ...' they illuminate ways in which the patient currently construes priorities.

On the other hand, they are also standard issues in the field of psychotherapy in which the patient may need to look further back, much further back. Here the answers may refer to (a) childhood sexual experimentation; (b) fear of father's return from work; (c) parents fighting or mother packing her bags and leaving; (d) fear of the dark; (e) feeling that he was not wanted himself, but only for what he could do for others; (f) earliest fears of not being adequately held or fed. So it is no great surprise that we may be back at the feeding/nurturing/holding experience, no matter whether it is the breast or the bottle held by loving hands.

During the course of my daily work as a psychotherapist I frequently recall the words of Charcot which Freud quoted so effectively. 'I learned ... to look at the same things again and again until they themselves begin to speak'. I find that it links so naturally with Peter Scott's question 'Looking back on it all now ...' in a setting where therapeutic space is unhurried and 'without limit of time', which allows 'things' to be looked at again and again until they themselves begin to speak. A patient said he never watched the news on television or read the papers, and another member of the group said 'You can't live on fantasies'. I suggest that participation in a therapeutic group keeps a patient 'watching the news about himself,' because he cannot avoid hearing about himself through the disclosures of others. The dynamic life of the therapeutic group means that he is perennially being stimulated to 'look back on it all now' and because of this he is also invited to look forward and ask himself this question: 'If that happened then, how have things changed now so that "without limit of time" will not mean for ever?"

\section{Psychotherapy within a forensic setting as a teaching resource}

In my view, both forensic psychiatry and dynamic psychotherapy have much untapped teaching potential for trainees who will ultimately work in the wider field of general psychiatry. This is because there is a specialized area of expertise at the particular point at which forensic and psychotherapeutic issues overlap. For example, other than interpretive skills may be needed by the therapist. He is called upon to act in the exigency of the present moment, if a group of aggressive psychopaths threatens to put aggressive fantasy into fact. Within the relative safety of conventional psychotherapeutic and psychoanalytic training institutes, it is unlikely that the supervisor will have had the experience which the trainee now wishes he could draw upon. This is of course the strength of a specialist unit such as the Portman Clinic in London, where psychoanalysts experience in forensic matters are able to offer psychotherapists supervision. Without this specialized experience, the supervisor may be ill at ease when the trainee he is supervising tells him that he thinks that his patient, hitherto a non-offender, is about to commit an offence.

Forensic psychiatrists have a reputation for being concerned with 'crunch issues' and for their down-to-earth directness. This can be a healthy corrective for the psychotherapist who may be tempted to make unproveable statements about intrapsychic dynamics. For example, he may report that a patient is more in touch with his feelings, only to be countered with the blunt question 'Will he rape again?'

Existential issues made evident by the psychotic offenderpatient make the psychiatrist 'Look at the same things again and again till they themselves begin to speak'.

The therapist's Weltowschouvang and poychotherapy training

It is generally accepted that one of the key issues in psychotherapy training is to put the therapist in touch with his own feelings. Nevertheless immersion in the world of forensic psychiatry faces the psychotherapist with a wider range of experience, so that the question becomes 'How much of the patient's experience can the therapist take?' Just what it is that allows the therapist to work without limit of time, at a depth and proximity not available in other settings, with patients for whom the 'basic crimes' are part of the reality of their history, raises issues other than the technicalities of training.

\section{Summary}

Forensic psychiatry offers dynamic psychotherapy: (a) Specialized expertise in working at that threshold over which Fantasy crosses into Fact. By any standards, a clinical concern of the highest priority. (b) Experience in which conventional aspects of training, such as timing and texturing of interventions, are reinforced. There is also the wider issue of whether the therapist can tolerate the patient's feelings. (c) The reminder of the nagging question 'Never mind all these elaborate formulations ... will he do it again?'

Dynamic psychotherapy offers forensic psychiatry: (a) Specialized expertise in reaching, unearthing, and hopefully changing, unconscious factors which are inaccessible to introspection. (b) Dynamic assessment of the patient, with special reference to endopsychic factors. Therapy and assessment are interwoven. (c) Particular supportive skills for patients who need 'a holding environment' in a 'holding environment', without limit of time.

The views presented in this paper are those of the author and do not necessarily reflect those of the Department of Health and Social Security. 